\title{
Corrigendum to: Operative Hysteroscopy Intravascular Absorption Syndrome: The Gynaecology's TURP Syndrome-A Case Report
}

\author{
Farnad Imani (101,* \\ ${ }^{1}$ Pain Research Center, Department of Anesthesiology and Pain Medicine, Iran University of Medical Sciences (IUMS), Tehran, Iran \\ "Corresponding author: Pain Research Center, Department of Anesthesiology and Pain Medicine, Iran University of Medical Sciences (IUMS), Tehran, Iran Email: \\ farnadimani@yahoo.com
}

Received 2019 December 15; Accepted 2019 December 16.

This corrects the article "Retracted Article: Operative Hysteroscopy Intravascular Absorption Syndrome: The Gynaecology's TURP Syndrome-A Case Report".

I, as the editor-in-chief and on behalf of the editorial board of the journal, - with our sincere regret to Daniela Coelho and our readers- declare that "Daniela Coelho" is not the co-author of this publication anymore. Due to a written claim by the added co-author (Daniela Coelho, on 22-10-2019, \#402462) and based on our investigations in line with the journal policy about Authorship Criteria, Authors' Responsibilities and Author Disclosure it is proved that submission of this manuscript (on 2019-02-04) by the main corresponding author (Ana Margarida Silva Santos) was done incorrectly without written permission from Daniela Coelho. Therefore, this is a case of malpractice in the ethics of Authorship Criteria and Daniela Coelho is not one of the authors of this publication. All communications with the corresponding author(Ana Margarida Silva Santos) and the complainant author (Daniela Coelho) recorded and reviewed in our editorial boards. Through this Correction, we declare that authors are changed as below:

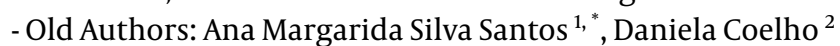

- New Author: Ana Margarida Silva Santos ${ }^{1, *}$

Kind Regards,

Prof. Farnad Imani, MD, FIPP

Editor-in-Chief 